\title{
COVID-19 Global Healthcare System Failures: The Desperate Need for a Paradigm Shift for Better Medical Materials ${ }^{\dagger}$
}

\section{Thomas J. Webster ${ }^{1, *}$}

1 Art Zafiropoulo Chair, SCOPUS Highly Cited Researcher, Department of Chemical Engineering, Northeastern University, Boston, MA 02115 USA

* Correspondence: websterthomas02@gmail.com;

$\dagger$ Presented at Materials Chemistry and Physics (Materials Chemistry 2020) - International e-Conference

Received: 16.09.2020; Revised: 20.09.2020; Accepted: 24.09.2020; Published: 27.09.2020

\begin{abstract}
COVID-19 has highlighted numerous failures in our global healthcare system, from a system focussed on centralized hospitals to a lack of platform technologies to treat viral outbreaks. This presentation will highlight new materials being developed to aid in COVID-19 prevention, detection, and therapy. Rather than waiting for a year or longer for vaccine development, this presentation will highlight how nanomaterials can be a platform technology modified to treat every new virus that comes along. It will also highlight the use of at-home sensors and diagnostic kits that make it easy for patients to determine if they have been exposed to viruses rather than going to a facility (i.e., hospital) in which their infection could spread. Overall, this presentation will demonstrate how new materials will better prepare us for our next viral outbreak and begin to heal our current global healthcare system, which has demonstrated significant failures during the COVID-19 pandemic.
\end{abstract}

Keywords: COVID-19; vaccine; viruses; global healthcare system.

(C) 2020 by the authors. This article is an open-access article distributed under the terms and conditions of the Creative Commons Attribution (CC BY) license (https://creativecommons.org/licenses/by/4.0/).

\section{Funding}

This research received no external funding.

\section{Acknowledgments}

This research has no acknowledgment.

\section{Conflicts of Interest}

The authors declare no conflict of interest. 